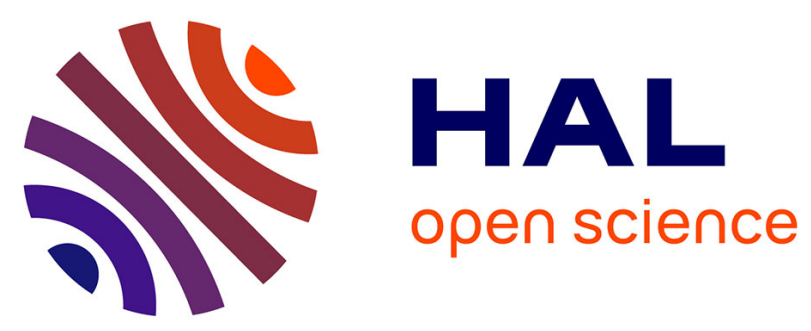

\title{
Solid state NMR spectroscopy as a powerful tool to investigate the location of fluorinated lipids in highly porous hybrid organic-inorganic nanoparticles
}

Marianna Porcino, Xue Li, Ruxandra Gref, Charlotte Martineau-corcos

\section{- To cite this version:}

Marianna Porcino, Xue Li, Ruxandra Gref, Charlotte Martineau-corcos. Solid state NMR spectroscopy as a powerful tool to investigate the location of fluorinated lipids in highly porous hybrid organic-inorganic nanoparticles. Magnetic Resonance in Chemistry, 2021, 59 (9-10), pp.1038-1047. 10.1002/mrc.5148 . hal-03195336

\section{HAL Id: hal-03195336 \\ https://hal.science/hal-03195336}

Submitted on 11 Apr 2021

HAL is a multi-disciplinary open access archive for the deposit and dissemination of scientific research documents, whether they are published or not. The documents may come from teaching and research institutions in France or abroad, or from public or private research centers.
L'archive ouverte pluridisciplinaire HAL, est destinée au dépôt et à la diffusion de documents scientifiques de niveau recherche, publiés ou non, émanant des établissements d'enseignement et de recherche français ou étrangers, des laboratoires publics ou privés. 


\title{
Solid state NMR spectroscopy as a powerful tool to investigate the location of
}

\section{fluorinated lipids in highly porous hybrid organic-inorganic nanoparticles}

\author{
Marianna Porcino, ${ }^{1}$ Xue Li, ${ }^{2}$ Ruxandra Gref,,${ }^{2, *}$ Charlotte Martineau-Corcos $\$, 3,4 *$ \\ ${ }^{1}$ CEMHTI UPR CNRS 3079, Université d'Orléans, F-45071 Orléans, France \\ ${ }^{2}$ Institut des Sciences Moléculaires d'Orsay, UMR CNRS 8214, Paris-Sud University, Université \\ Paris Saclay, 91400 Orsay, France \\ ${ }^{3}$ ILV UMR CNRS 8180, Université de Versailles St-Quentin en Yvelines, Université Paris Saclay, \\ 78035 Versailles, France \\ ${ }^{4}$ current address : CortecNet, 7 avenue du Hoggar, 91940, Les Ulis, France \\ Corresponding author: ruxandra.gref@universite-paris-saclay.fr, charlotte.martineau@uvsq.fr, \\ ccorcos@.cortecnet.com
}

\section{Orcid}

Charlotte Martineau-Corcos: 0000-0003-1887-1042

Ruxandra Gref: 0000-0002-7869-0908

Xue Li : 0000-0003-0254-643X

Keywords: nanoporous solids, Metal-Organic-frameworks, Drug delivery systems, ${ }^{27} \mathrm{Al}$ MAS NMR, ${ }^{19} \mathrm{~F}$ MAS NMR

\begin{abstract}
Nanosized metal-organic frameworks (nanoMOFs) have emerged as a new class of biodegradable and non-toxic nanomaterials of high interest for biomedical applications thanks to
\end{abstract}


the possibility to load large amounts of a wide variety of therapeutic molecules in their porous structure. The surface of the highly porous nanoMOFs is usually engineered to increase their colloidal stability, tune their interactions with the biological environment and allow targeting specific cells or organs. However, the atomic-scale analysis of these complex core-shell materials is highly challenging. In this study, we report the investigation of aluminium-based nanoMOFs containing two fluorinated lipids by solid-state NMR spectroscopy, including ${ }^{27} \mathrm{Al},{ }^{1} \mathrm{H}$ and ${ }^{19} \mathrm{~F}$ MAS NMR. The ensemble of NMR data provides a better understanding of the localization and conformation of the fluorinated lipids inside the pores or on the nanoMOF surface.

\section{Introduction}

Nanosized metal-organic frameworks (nanoMOFs) have emerged as a new class of biodegradable and non-toxic nanomaterials of high interest for biomedical applications thanks to the possibility to load large amounts (within the $20-70 \mathrm{wt} \%$ range) of a wide variety of therapeutic molecules in the porous structure of MOFs. ${ }^{1-5}$ The surface of the highly porous nanoMOFs is engineered to increase their colloidal stability, tune the interactions with the biological environment and allow targeting specific cells or organs. ${ }^{6,7}$

Poly(ethylene glycol) (PEG) is a well-known coating material shown to drastically increase the stealth behavior of the NPs towards the immune system. ${ }^{8-10}$ In 2015 Agostoni et al. ${ }^{11}$ investigated the possibility to directly coat the surface of the MIL-100(Fe) nanoMOFs (MIL stands for Material of the Institute Lavoisier) with PEG chains. Despite, reaching around $17 \mathrm{wt} \%$ PEG contents in the nanoMOFs, it was found that the BET surface area of the nanoMOF dramatically decreased, from $1350 \pm 100 \mathrm{~m}^{2} \cdot \mathrm{g}^{-1}$ to around $350 \mathrm{~m}^{2} \cdot \mathrm{g}^{-1}$ after incubation with PEG solutions. A partial filling and/or blocking of the pores by PEG chains was suspected as PEG chains can 
penetrate into the pores by reptation, since their section $(3.1 \AA)$ is smaller than the size of the windows of the nanoMOF. This partial filling/blockage of the pores was detrimental to drug incorporation. Further studies by the same groups demonstrated that bulky coating materials, with rigid sections larger than the nanoMOF windows, could be firmly attached at their surface without reducing the surface areas. For instance, stable coatings were achieved with a series of modified cyclodextrins. ${ }^{12,13}$

More recently, FDA-approved lipids and PEG-lipid conjugates were used to coat the surface of nanoMOFs by a rapid and convenient solvent-exchange deposition method. ${ }^{14}$ It was shown that nanoMOF surface modification with lipids affords a better control over drug release and particle degradation. Moreover, nanoMOFs acted as "Trojan horses" carrying anticancer drugs inside cancer cells to eradicate them. Most interestingly, in vitro investigations showed that the PEG-coated nanoMOFs escaped the capture by macrophages. The nanoMOF surface area was not affected by the presence of the coating, suggesting that PEG chains did not penetrate inside the pores. However, no direct evidence was given on PEG location.

${ }^{19}$ F-labeled PEG-lipid conjugates are also interesting as they might be considered as a way to confer magnetic resonance imaging (MRI) properties to the nanoMOFs, allowing the direct detection of labelled cells, for unambiguous identification and quantification, and circumventing some drawbacks related to the commonly used metal-based contrast agents. ${ }^{15-17}$ Good efficiency requires the fluorinated moieties to be loaded in the pores of the nanoMOFs.

In all the mentioned systems, knowledge about the localization of the fluorinated PEGlipid conjugates or coatings is still to be uncovered and of utmost importance. Therefore, the present study aims at addressing this topic by using state of the art magic-angle spinning (MAS) solid-state NMR spectroscopy (ssNMR). Numerous examples indeed show the efficient use of 
ssNMR as a tool to characterize MOFs ${ }^{1819}$ and MOF-based drug delivery systems. ${ }^{20-24}$ In particular, two-dimensional (2D) MAS NMR experiments can be useful to obtain information about the localization of molecules in the pores or the interactions at play in these systems. ${ }^{25,26}$

The materials under study are MIL-100(Al) nanoMOFs, which were selected because they are the diamagnetic analogues of MIL-100(Fe). These nanoparticles named here nanoMIL-100(Al) were impregnated with two different F-labeled lipid conjugates (Figure 1): methyl perfluorooctanoate (FO), supposedly small enough to enter in the pores of the MOF, and 1palmitoyl-2-(16-fluoropalmitoyl)-sn-glycero-3-phosphocholine (FP), supposedly too large to enter in the pores of the MOF.

In a first step, ${ }^{27} \mathrm{Al}$ MAS NMR spectroscopy was considered to probe the localization of the F-lipids because the ${ }^{27} \mathrm{Al}$ is present only in the MOF and ${ }^{19} \mathrm{~F}$ only in the lipid, which could provide good bulk/surface selectivity as was shown for the ${ }^{27} \mathrm{Al}-{ }^{31} \mathrm{P}$ spin pair in the case for cyclodextrin phosphate-coated nanoMIL-100(Al). ${ }^{27}$ It is nowadays easy to determine ${ }^{27} \mathrm{Al}$ chemical shifts and quadrupolar parameters (quadrupolar coupling constant and asymmetry parameter) from a single-pulse or a multiple-quantum MAS (MQMAS) or satellite transition (STMAS) NMR spectrum. Valuable information about connectivity between ${ }^{27} \mathrm{Al}$ nucleus and other neighboring nuclei can also be available using through bond ( $J$-based experiments) or through space ( $D$-based experiments), either as heteronuclear $\left({ }^{27} \mathrm{Al}-\mathrm{X}\right)$ or homonuclear $\left({ }^{27} \mathrm{Al}-{ }^{27} \mathrm{Al}\right)$ ${ }^{28-35}$ experiments can be performed in porous solids. In principle, ${ }^{27} \mathrm{Al}$ is therefore an ideal probe for numerous solids, ${ }^{36}$ including MOFs (list of reference not exhaustive). ${ }^{37-4445}$ However, we found some limits of ${ }^{27} \mathrm{Al}$ double-resonance spectroscopy in our samples, which could be circumvented using two-dimensional (2D) ${ }^{1} \mathrm{H}-{ }^{1} \mathrm{H}$ and ${ }^{19} \mathrm{~F}-{ }^{1} \mathrm{H}$ NMR correlation. These experiments provide unambiguous localization of both lipids inside and outside the MOF. 
(a)

methyl perfluorooctanoate

(FO)<smiles>C=C(CCCCCCCCCCCCCC(F)(F)F)OC[C@H](COP(=O)(O)OCC[N+](C)(C)C)OC(=O)CCCCCCCCCCCC(C(F)(F)F)(C(F)(F)F)C(F)(F)F</smiles>

(b)

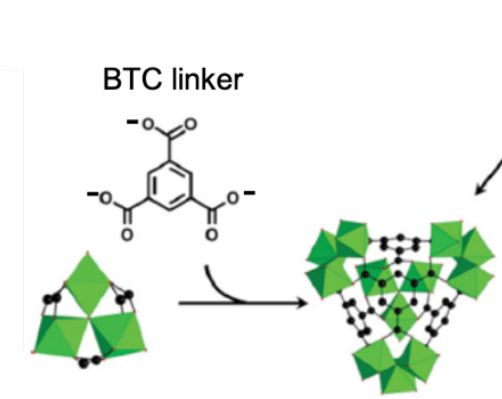

Al tricluster

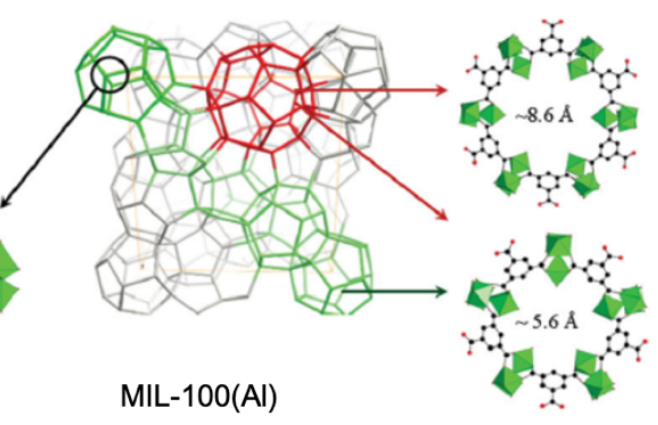

Pore Windows

(c)

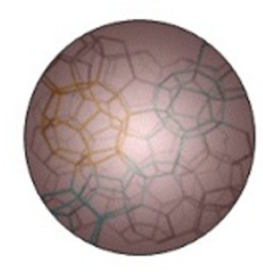

nanoMIL-100(Al)

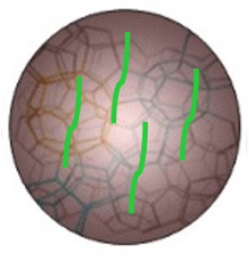

FO@nanoMIL-100(Al)

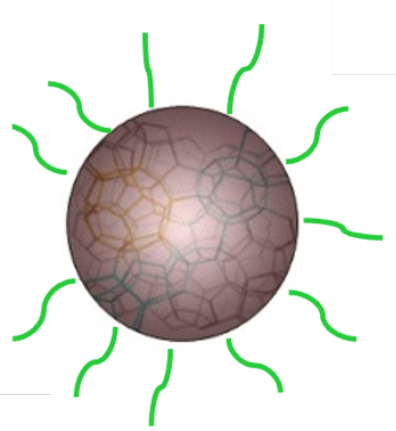

FP@nanoMIL-100(Al)

Figure 1. (a): chemical structure of methyl perfluorooctanoate FO (middle) and 1palmitoyl-2-(16-fluoropalmitoyl)-sn-glycero-3-phosphocholine FP (right). (b): Structure of MIL100(Al) based on the association of BTC linker and Al triclusters. The pore openings are shown on the right part. (c): Schematic structure of nanoMIL-100(Al) (left) and hypothesized localization of FO (middle) and FP (right) inside and outside the nanoMOFs, respectively. 


\section{Experimental section}

\section{Materials}

1,3,5-benzenetricarboxylic acid (trimesate, 95\%, Sigma-Aldrich, France) aluminum nitrate nonahydrate (98\%, Sigma-Aldrich, France), trimethyl trimesate (98\%, Sigma-Aldrich, SaintQuentin-Fallavier, France) and absolute methanol (99\%, Carlo Erba, France) were used for the synthesis of nanoMOFs. FO and FP were purchased from Sigma-Aldrich (France) and Avanti Polar Lipids (France), respectively. Absolute ethanol (99\%, Carlo Erba, France) was used for FP@nanoMIL-100. Water was purified by a Millipore MilliQ system.

\section{Synthesis and Characterization}

Synthesis of nanoMIL-100(Al). MIL-100 (Al) nanoMOFs were synthesized as previously reported.$^{46}$ Briefly, aluminum nitrate nonahydrate $(1.43 \mathrm{~g})$ and trimethyl trimesate $(1.21 \mathrm{~g})$ were dissolved in $20 \mathrm{~mL}$ of water and then mixed with $4 \mathrm{~mL}$ of nitric acid $(4 \mathrm{mM})$ at room temperature followed by microwave assisted heating at $210{ }^{\circ} \mathrm{C}$ for $30 \mathrm{~min}$ under stirring. The synthesized nanoMIL-100 (Al) were harvested by centrifugation $(10,000 \mathrm{~g}, 15 \mathrm{~min})$ and then activated by dispersing them into $50 \mathrm{~mL}$ of methanol overnight under vigorous stirring, followed by centrifugation and storage in methanol until further use. The nanoMOF hydrodynamic diameters and size distributions were determined by dynamic light scattering (DLS, Malvern Nano-ZS, Zetasizer Nano series, France).

Preparation of FO@nanoMIL-100.100 mg of nanoMIL-100 (Al)were incubated in 2 mL of pure FO at room temperature for two days under gentle shaking. After FO loading by impregnation, the particles were washed with ethanol twice and dried at $50^{\circ} \mathrm{C}$ overnight. 
Preparation of FP@nanoMIL-100. NanoMOFs (1 mL, 40 mg/mL) aqueous suspension was mixed with $4 \mathrm{~mL}$ of lipid alcoholic solution containing $4 \mathrm{mg}$ of FP. Subsequently, $45 \mathrm{ml}$ of water were rapidly added using an electronic pipette. The weight ratio between FP and nanoMOF was $1: 10$.

BET surface area characterization. Prior to the measurement, the samples were centrifuged at $10,000 \mathrm{~g}$ for $20 \mathrm{~min}$ and the pellets were recovered and dried at $70^{\circ} \mathrm{C}$ for $24 \mathrm{~h}$. The porosity of the empty nanoMIL-100, FO@nanoMIL-100 and FP@nanoMIL-100 was characterized using porosimetry (ASAP 2020, Micromeritics, USA) by nitrogen sorption experiments at $-196{ }^{\circ} \mathrm{C}$ after degassing at $100{ }^{\circ} \mathrm{C}$ for $15 \mathrm{~h}$ under secondary vacuum.

\section{Solid-state NMR Spectroscopy}

The ${ }^{1}$ H MAS NMR spectra were recorded at a magnetic field of 17.6 T, using a Bruker 750 MHz WB NMR spectrometer and a HX $2.5 \mathrm{~mm}$ probe. The spectra were acquired using a Hahn echo pulse sequence, with a $90^{\circ}$ pulse duration of $2.25 \mu \mathrm{s}$, an inter-pulse delay synchronized with one rotor period and a spinning rate of $25 \mathrm{kHz}$. The recycle delay was set to $1 \mathrm{~s}$ and 16 transients were recorded for each sample. The ${ }^{1} \mathrm{H}$ chemical shifts were referenced to TMS. The ${ }^{13} \mathrm{C}$ CPMAS NMR spectra were recorded at a magnetic field of $9.4 \mathrm{~T}$, using a HX $4 \mathrm{~mm}$ probe, with a spinning rate of $10 \mathrm{kHz}$. The contact time was set to $3.5 \mathrm{~ms}$, a recycle delay of $3 \mathrm{~s}$ and the initial 90 pulse on ${ }^{1} \mathrm{H}$ to $3.1 \mu$ s with a Radio Frequency (RF) field of $80 \mathrm{kHz} .{ }^{1} \mathrm{H}$ SPINAL-64 decoupling was applied during the ${ }^{13} \mathrm{C}$ acquisition. The ${ }^{13} \mathrm{C}$ chemical shifts are referenced to TMS. The ${ }^{27} \mathrm{Al}$ MAS NMR spectra were recorded at the same magnetic field and same probe. The recycle delay was set to $0.3 \mathrm{~s}$, the $90^{\circ}$ pulse to $2.5 \mu$ s with a RF field of $33 \mathrm{kHz}$. The ${ }^{27} \mathrm{Al}$ chemical shifts are referenced to a $\mathrm{Al}\left(\mathrm{NO}_{3}\right)_{3}$ solution at $0 \mathrm{ppm}$. The ${ }^{27} \mathrm{Al}$ MQMAS (Multi-Quantum Magic-Angle Spinning) experiments were carried out at 17.6 T (Larmor Frequency of $195 \mathrm{MHz}$ ), using a HX $2.5 \mathrm{~mm}$ 
probe with a spinning rate of $25 \mathrm{kHz}$, using a triple-quantum z-filtered pulse sequence ${ }^{47}$ and are shown after a shearing transformation. The ${ }^{1} \mathrm{H}^{-27} \mathrm{Al} \mathrm{CP}-\mathrm{HETCOR}$ spectra were recorded at a magnetic field of $9.4 \mathrm{~T}$, using a HX $4 \mathrm{~mm}$ probe, with a spinning rate of $10 \mathrm{kHz}$. The contact times were set to 1 and $5 \mathrm{~ms}$, a recycle delay of $1 \mathrm{~s}$ and the initial 90 pulse on ${ }^{1} \mathrm{H}$ to $3.1 \mu$ s with a RF field of $80 \mathrm{kHz}$. The RF field for the ${ }^{27} \mathrm{Al}$ and ${ }^{1} \mathrm{H}$ during the contact time are $10 \mathrm{kHz}$ and $44 \mathrm{kHz}$, respectively. ${ }^{1} \mathrm{H}$ SPINAL-64 decoupling was applied during the ${ }^{27} \mathrm{Al}$ acquisition. $250 \mathrm{t}_{1}$ slices with 384-640 transients were co-added. The States procedure provided phase sensitive 2D NMR spectra. The ${ }^{27} \mathrm{Al}\left\{{ }^{1} \mathrm{H}\right\} \quad D$-HMQC ${ }^{48-50}$ (dipolar-Heteronuclear multiquantum correlation) 2D experiment was recorded at $20 \mathrm{~T}$, and MAS frequency of $60 \mathrm{kHz}$ in a $1.3 \mathrm{~mm}$ probe. $\mathrm{R} 4^{2}{ }_{1}{ }^{51,52}$ was used as the recoupling sequence in order to reintroduce ${ }^{1} \mathrm{H}-{ }^{27} \mathrm{Al}$ heteronuclear dipolar interaction, with $1.4 \mathrm{~ms}$ recoupling duration. No ${ }^{1} \mathrm{H}$ decoupling was applied. $80 \mathrm{t}_{1}$ slices with 1024 transients were co-added. The States-TPPI procedure provided a phase sensitive 2D NMR spectrum.

The ${ }^{19} \mathrm{~F}$ MAS NMR spectra were recorded at a $11.6 \mathrm{~T}$ magnetic field and using a ${ }^{1} \mathrm{H}-{ }^{19} \mathrm{~F}-\mathrm{X}$ triple-resonance $2.5 \mathrm{~mm}$ probe.$^{53}$ The spectra were acquired using a Hahn echo pulse sequence, with a $90^{\circ}$ pulse duration of $2.1 \mu \mathrm{s}$, an inter-pulse delay synchronized with one rotor period and a spinning rate of $25 \mathrm{kHz} .{ }^{19} \mathrm{~F}$ chemical shifts are referenced to $\mathrm{C}_{6} \mathrm{~F}_{6}$. No ${ }^{1} \mathrm{H}$ decoupling was applied. The ${ }^{1} \mathrm{H}-{ }^{1} \mathrm{H}$ RFDR and ${ }^{19} \mathrm{~F}-{ }^{1} \mathrm{H}$ CPMAS NMR spectra were recorded at the same magnetic field. The RF field for ${ }^{1} \mathrm{H} 180^{\circ}$ pulse of the RFDR was set to $100 \mathrm{kHz}$. The mixing time for the RFDR was set to $5 \mathrm{~ms} .800 \mathrm{t}_{1}$ slices with 16 transients were co-added. The RF field for the ${ }^{19} \mathrm{~F}$ and ${ }^{1} \mathrm{H}$ during the contact time are $100 \mathrm{kHz}$ on both channels. The States procedure provided a phase sensitive 2D NMR spectrum. For the CPMAS experiment, the contact time was set to $0.5 \mathrm{~ms} .256$ $\mathrm{t}_{1}$ slices with 64 transients were co-added, with a recycle delay of $1 \mathrm{~s}$. 
All spectra were analysed using the DmFit software. ${ }^{54}$ For all experiments, the samples were packed in the rotors as received.

\section{Results and Discussion}

NanoMIL-100(Al) was successfully synthesized with mean diameter of $269 \pm 21 \mathrm{~nm}$ as determined by DLS (Figure S1). The BET surface area reached $1750 \pm 60 \mathrm{~m}^{2} \cdot \mathrm{g}^{-1}$, in agreement with previously reported data. ${ }^{46}$ After FO loading, the BET surface area was dramatically reduced to $960 \pm 50 \mathrm{~m}^{2} \cdot \mathrm{g}^{-1}$, indicating that FO partially occupied the nanoMIL-100 (Al) pores. Indeed, the molecular section of linear molecules such as FO is smaller than the nanoMOF large windows which can explain why this lipid penetrated inside the porosity. ${ }^{11}$ In recent studies, it was shown that bulkier lipids such as DOPC (1,2-dioleoyl-sn-glycero-3-phosphocholine) and PEG-DSPE (1, 2-Distearoyl-sn-glycero-3-phospho-ethanolamine-Poly(ethylene glycol)) remained anchored at the nanoMOF surface without penetrating inside the pores. ${ }^{14}$ The porosity of the nanoMOFs was not altered by surface modifications with these FDA-approved lipids $\left(1519 \pm 50 \mathrm{~m}^{2} \cdot \mathrm{g}^{-1}, 1486 \pm 70\right.$ $\mathrm{m}^{2} \cdot \mathrm{g}^{-1}$, and $1547 \pm 80 \mathrm{~m}^{2} \cdot \mathrm{g}^{-1}$ for uncoated nanoMOFs, lipid coated nanoMOFs with and without DSPE-PEG 2000, respectively, see Figure S2). Similarly, in this study, nanoMOFs coated with FP which has bulky structure as these previously studied lipids exhibited similar BET surface area $\left(1500 \pm 70 \mathrm{~m}^{2} \cdot \mathrm{g}^{-1}\right)$, as compared to the DOPC or DSPE-PEG coated nanoMOFs. Note that for both samples, we could not quantify the amount of lipid loaded/coated.

If these first results hints in the localization of the FO and FP lipids respectively inside and outside the pores of the nanoMOF, further confirmation was sought by solid-state NMR spectroscopy. 


\section{1D MAS NMR}

Figure 2 shows ${ }^{1} \mathrm{H},{ }^{27} \mathrm{Al}$ and ${ }^{13} \mathrm{C}$ NMR spectra of the two F-lipid samples in comparison with pure nanoMIL-100(Al). The ${ }^{1} \mathrm{H}$ resonances of the lipids can be readily observed: the $-\mathrm{OCH}_{3}$ of the methyl perfluorooctanoate around $3.5 \mathrm{ppm}$ and the palmitoyl $\mathrm{CH}_{2}$ in the range 0 to $3 \mathrm{ppm}$ as well as the ${ }^{1} \mathrm{H}$ resonances of the MOF linker at $9.1 \mathrm{ppm}$. One can notice a difference in the content of water between the three samples, in particular the content is much less in the FO@nanoMIL100(Al). This might be a first hint that in this formulation, the pores are partly filled with the fluorinated polymer, hence much less water is present.

No significant change can be noticed on the 1D ${ }^{27} \mathrm{Al}$ MAS NMR spectra of the three samples (Figure 2), indicating little changes in the environment of aluminum upon F-lipid loading/coating and consequently little interaction with the nanoMOF. This is further confirmed by the ${ }^{27}$ Al MQMAS NMR spectra (Figure 3), in which one can notice the two characteristic bulk and surface signals, already observed in the pure nanoMIL-100(Al). ${ }^{27}$

All the ${ }^{13} \mathrm{C}$ resonances belonging to the nanoMOFs can be identified in the ${ }^{13} \mathrm{C}$ CPMAS NMR spectra (Figure 2) of FO@nanoMIL-100(Al) and FP@nanoMIL-100(Al): the resonances around $170 \mathrm{ppm}$ and $130 \mathrm{ppm}$ respectively belong to the $\mathrm{CO}$ and aromatic carbon atoms of the linker of nanoMIL-100(Al), with their respective spinning sidebands located around 70 and 30 ppm. This indicates that the impregnation does not alter significantly the MOF structure. On the ${ }^{13} \mathrm{C}$ CPMAS NMR spectrum of FP@nanoMIL-100(Al), ${ }^{13} \mathrm{C}$ resonances of the palmitoyl lipid are difficult to observe. Their low intensity is could be due to i) possibly low amount of coating molecules (note that the exact amount of lipid in the final products could not be determined), ii)

potential mobility of the lipid which reduces the ${ }^{1} \mathrm{H} \rightarrow{ }^{13} \mathrm{C}$ polarization transfer efficiency. For FO@nanoMIL-100(Al), only the peak belonging to the $-\mathrm{OCH}_{3}$ around $20 \mathrm{ppm}$ may be identified 
in addition to the resonances belonging to the trimesate linker of the nanoMOF. It is difficult to observe ${ }^{13} \mathrm{C}$ resonances from CFx groups since the ${ }^{13} \mathrm{C}$ CPMAS NMR spectra were acquired using a ${ }^{1} \mathrm{H} \rightarrow{ }^{13} \mathrm{C}$ CPMAS polarization transfer.

Finally, on the ${ }^{19} \mathrm{~F}$ MAS NMR spectra, all resonances of the fluorinated lipids can be identified and assigned (Figure 4). In detail, for the FO@nanoMIL-100(Al) (Figure 4a), the ${ }^{19} \mathrm{~F}$ resonances of the $\mathrm{COCF}_{2}$ moieties are located around $-80 \mathrm{ppm}$, the ones of the $\mathrm{CF}_{2}$ groups are located between -115 and $-125 \mathrm{ppm}$ and finally the ones of the $\mathrm{CF}_{3}$ groups are around $-127 \mathrm{ppm} .{ }^{55}$ Regarding FP@nanoMIL-100(Al) (Figure 4b), the ${ }^{19} \mathrm{~F}$ resonance of the $\mathrm{CFH}_{2}$ are located around $-215 \mathrm{ppm}$, which is $40 \mathrm{ppm}$ shifted compared to neet FO (-175 ppm). ${ }^{56}$ This shift might be due do the drug loading that generate interactions between the polymer and the MOF.

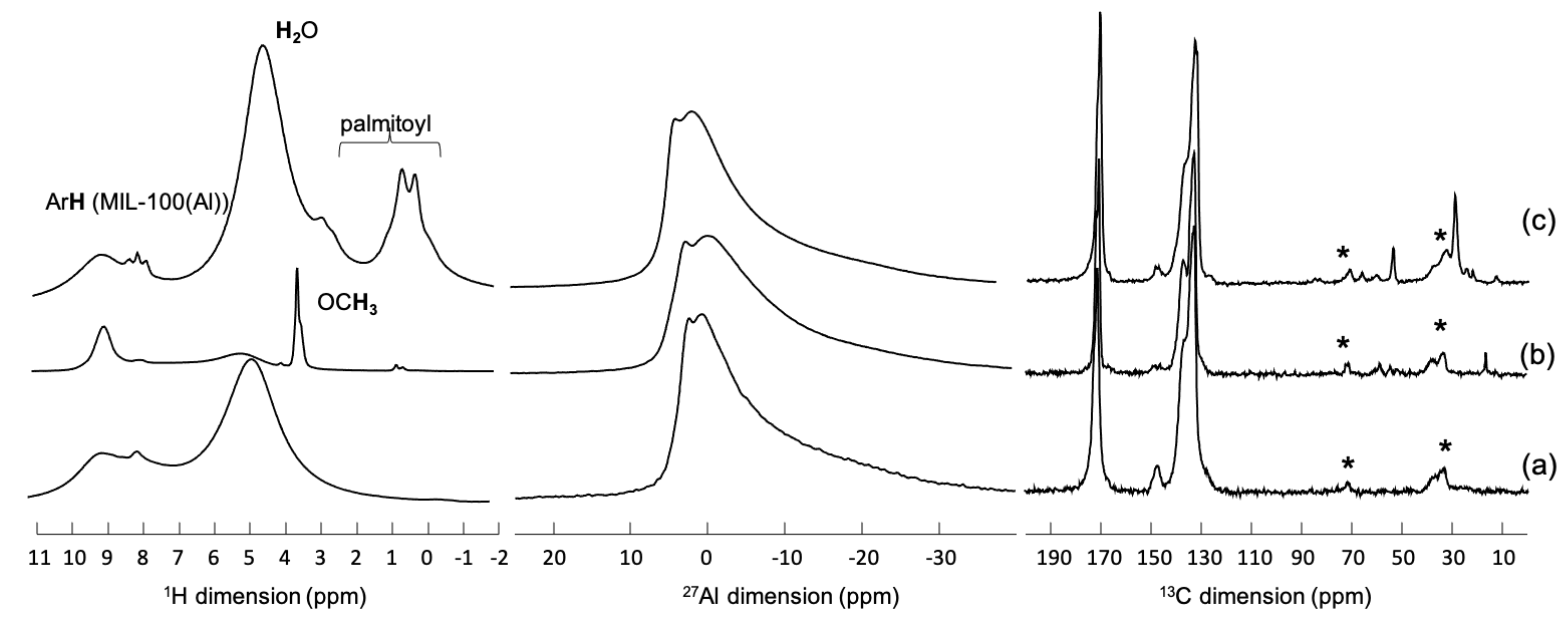

Figure 2. ${ }^{1} \mathrm{H},{ }^{27} \mathrm{Al},{ }^{13} \mathrm{C}$ MAS NMR spectra of (a) pure nanoMIL-100(Al), (b) FO@nanoMIL100(Al) and (c) FP@nanoMIL-100(Al) The lines on the ${ }^{1} \mathrm{H}$ MAS NMR spectrum are assigned.

On the ${ }^{13} \mathrm{C}$ CPMAS NMR spectrum, the spinning sidebands are indicated by stars. 

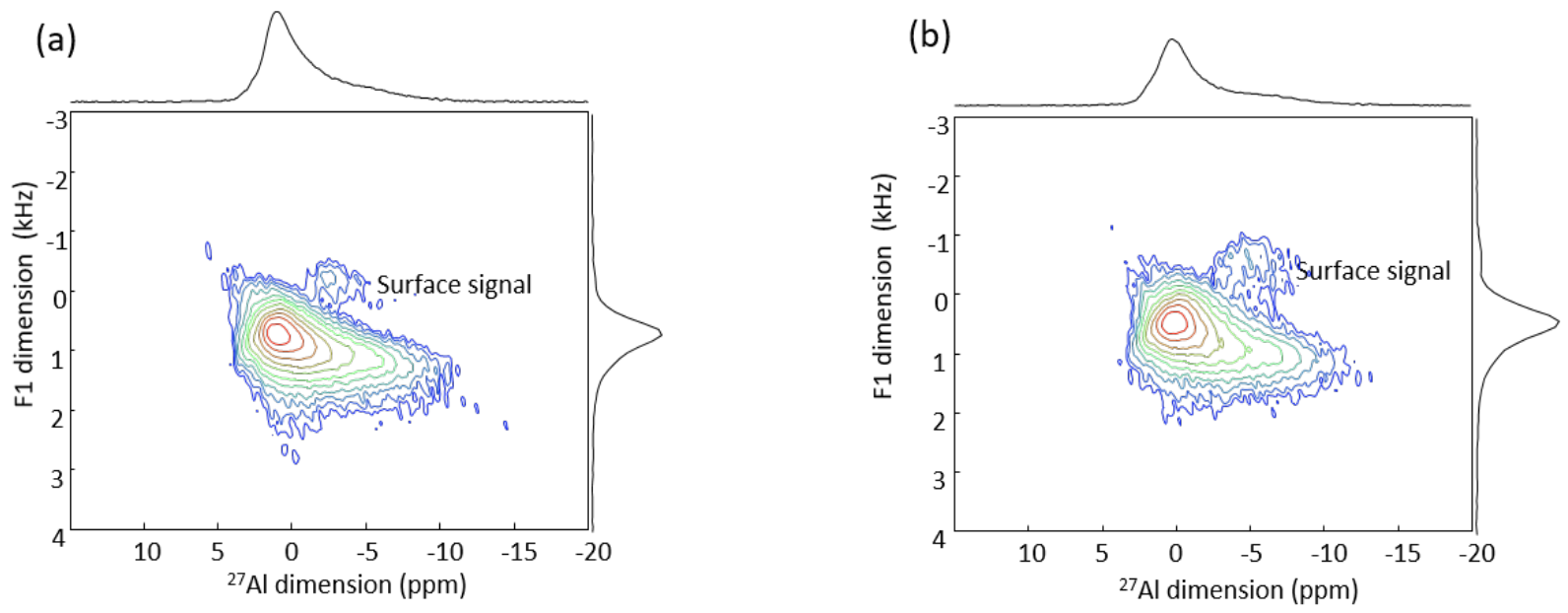

Figure 3. ${ }^{27} \mathrm{Al}$ MQMAS NMR spectra of (a) FO@nanoMIL-100(Al) and (b) FP@nanoMIL100(Al).
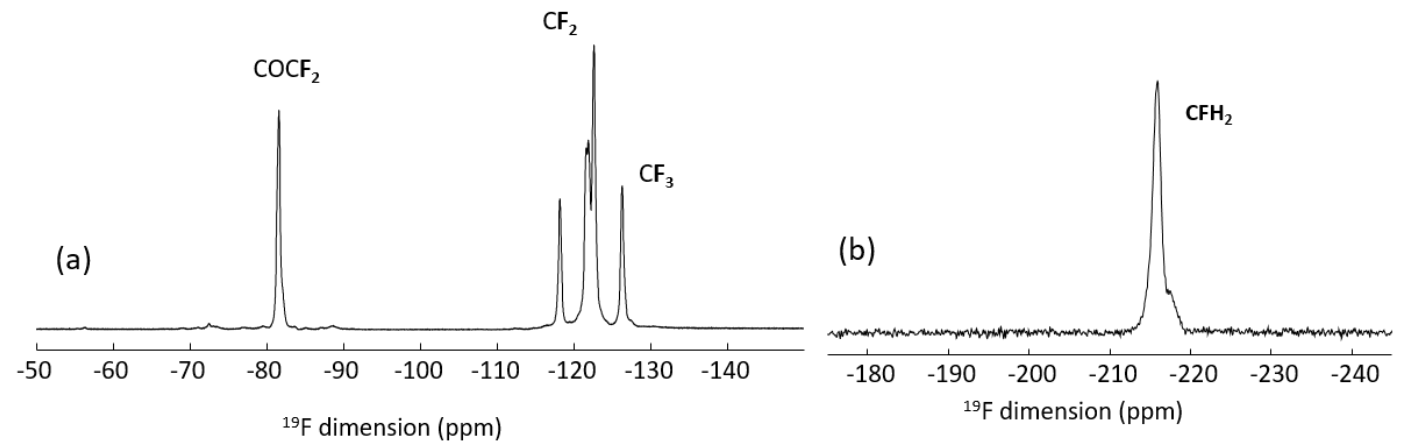

Figure 4. ${ }^{19} \mathrm{~F}$ MAS NMR spectra of (a) FO@nanoMIL-100(Al) and (b) FP@nanoMIL-100(Al). The lines are assigned.

\section{2. ${ }^{27} \mathrm{Al}-{ }^{1} \mathrm{H}$ 2D MAS NMR}

In a first step, ${ }^{19} \mathrm{~F}^{27} \mathrm{Al} 2 \mathrm{D}$ experiments were carried out to probe the fluorinated lipid localization. However, we could not obtain a good signal. This could be due to high mobility of the lipids, or small dipolar coupling that prevented efficient CP transfer. We therefore moved to ${ }^{1} \mathrm{H}-{ }^{27} \mathrm{Al}$ investigations, since the characteristic peaks of the lipids have ${ }^{1} \mathrm{H}$ resonances $(0-5 \mathrm{ppm}$ 
range) that do not overlap with those of the nanoMOFs (aromatic protons in the 8-10 ppm range). For these experiments, we started with ${ }^{1} \mathrm{H} \rightarrow{ }^{27} \mathrm{Al}$ CPMAS transfer. In the ${ }^{1} \mathrm{H}-{ }^{27} \mathrm{Al}$ 2D CP-HETCOR NMR spectrum of pristine nanoMIL-100(Al) (Figure 5a), the expected correlation between the protons of the trimesate linker and the neighboring aluminum is observed. A second correlation peak is observed between the aluminum and the water present in the pores and/or on the aluminum tri-cluster, whatever the chosen contact time between 1 and $5 \mathrm{~ms}$ (see Figure S3). It is well known that increased resolution might be obtained at higher magnetic field for the ${ }^{27} \mathrm{Al}$ nucleus. Therefore, we also performed ${ }^{1} \mathrm{H}-{ }^{27} \mathrm{Al} 2 \mathrm{D}$ experiments at $20.0 \mathrm{~T}$. While ${ }^{1} \mathrm{H}-{ }^{27} \mathrm{Al}$ CPMAS can be very efficient at fast spinning spee (60 kHz or more), ${ }^{57}$ we chose to work at lower MAS frequency $(20 \mathrm{kHz})$ and larger rotor size since the F-lipids content is low in our sample. It was shown that under these conditions ${ }^{27} \mathrm{Al}\left\{{ }^{1} \mathrm{H}\right\}$ through space $D$-HMQC is more efficient than $\mathrm{CP}$ because the experiment is less sensitive to offset issues, in particular for compounds with aluminum atoms in more than one type of coordination. ${ }^{58}$ For nanoMIL-100(Al), the ${ }^{27} \mathrm{Al}\left\{{ }^{1} \mathrm{H}\right\} D$-HMQC NMR spectrum (Figure $5 \mathrm{~b}$ ) shows the same expected correlation peak between the aluminum of the framework and the trimesate protons as was observed with the CPMAS experiment Figure 5a. However, here, no correlation with water was observed. This could be due to i) the mobility of the water molecules that prevent efficient recoupling during the $D$-HMQC sequence, and/or ii) the too short recoupling time used here (limited by the short ${ }^{27} \mathrm{Al}$ transverse relaxation time $\mathrm{T}_{2}$ of about $3 \mathrm{~ms}$ ). To see if we could detect correlation between the MOF linker and larger (less mobile) species loaded inside the pores, we performed similar ${ }^{1} \mathrm{H}-{ }^{27} \mathrm{Al} 2 \mathrm{D}$ CP-HETCOR and ${ }^{27} \mathrm{Al}\left\{{ }^{1} \mathrm{H}\right\} D$-HMQC NMR experiments on nanoMIL-100(Al) which pores were known to be loaded with the adenosine triphosphate drug molecule (ATP).${ }^{27}$ However, here again, the correlation peak between the drug and the MOF could not be detected on either spectrum (Figure S4). At last attempt, we performed ${ }^{1} \mathrm{H}-{ }^{27} \mathrm{Al}$ CPMAS on 
both F-lipid impregnated nanoMIL-100(Al), which also did not show any correlation between the lipid and the nanoMOF (Figure S5). For the present study, this is a limitation because we are interested in finding the localization of the fluorinated lipids. We therefore switched to ${ }^{1} \mathrm{H}-{ }^{1} \mathrm{H}$ and ${ }^{1} \mathrm{H}-{ }^{19} \mathrm{~F} 2 \mathrm{D}$ NMR spectroscopy.

(a)

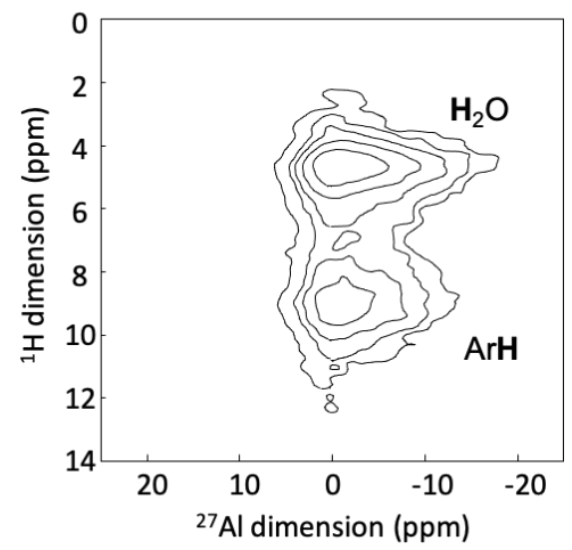

(b)

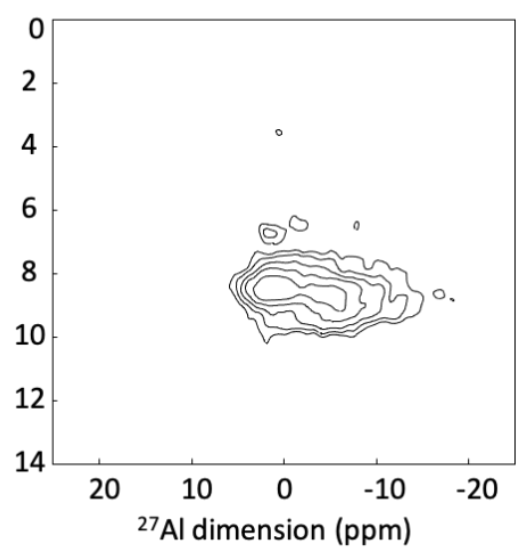

Figure 5. (a) ${ }^{1} \mathrm{H} \rightarrow{ }^{27} \mathrm{Al} \mathrm{CP}$-HETCOR $\left(\mathrm{B}_{0}=9.4 \mathrm{~T}\right)$ and $(\mathrm{b}){ }^{27} \mathrm{Al}\left\{{ }^{1} \mathrm{H}\right\} D$-HMQC $\left(\mathrm{B}_{0}=20 \mathrm{~T}\right)$ MAS NMR spectra of nanoMIL-100(Al).

\section{3. ${ }^{1} \mathrm{H}-{ }^{1} \mathrm{H}$ and ${ }^{1} \mathrm{H}-{ }^{19} \mathrm{~F}$ 2D MAS NMR}

${ }^{1} \mathrm{H}-{ }^{-1} \mathrm{H}$ (Figure 6) and ${ }^{19} \mathrm{~F}-{ }^{-1} \mathrm{H}$ (Figure 7) 2D NMR experiments were recorded to detect close spatial proximities between the proton/fluorine of the lipids and the protons of the MOF. In the ${ }^{1} \mathrm{H}-{ }^{1} \mathrm{H}$ 2D RFDR NMR spectrum of (Figure 6a) of FO@nanoMIL-100(Al), the main correlation peak is between the small amount of water present in the pores and the protons of the trimesate linker. However, we could not observe the expected correlation between the trimesate linker and the $\mathrm{CH}_{3}$ of the FO lipid. In the ${ }^{1} \mathrm{H}-{ }^{1} \mathrm{H}$ 2D RFDR NMR spectrum of FP@nanoMIL-100(Al) (Figure 6b), in addition to the water-trimesate correlation, peaks of small intensity are observed between the lipid and the trimesate linker. Since the FP lipid is too bulky to enter in the pores of the 
nanoMOF, these observed interactions take place between the lipid and the trimesate linkers located on the nanoparticle surface, indicating a good surface covering property of the lipid.
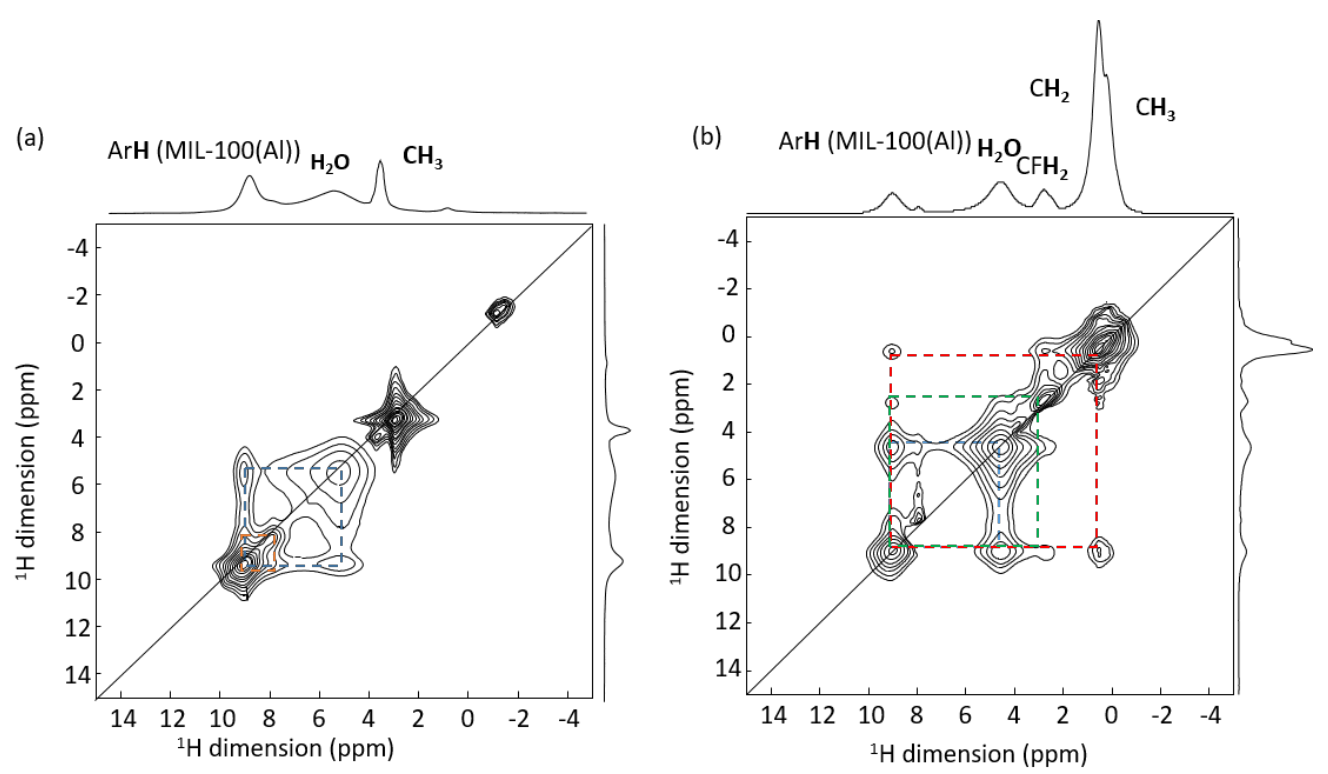

Figure 6. ${ }^{1} \mathrm{H}-{ }^{1} \mathrm{H}$ 2D MAS NMR RFDR spectra of (a) FO@nanoMIL-100(Al) and (b) FP@nanoMIL-100(A1) recorded with a mixing time of $5 \mathrm{~ms}$.

To go further, ${ }^{19} \mathrm{~F}-{ }^{1} \mathrm{H}$ CPMAS $2 \mathrm{D}$ NMR experiments were recorded (Figure 7 ). In the ${ }^{19} \mathrm{~F}$ ${ }^{1} \mathrm{H}$ 2D NMR spectrum of (Figure 7a) of FO@nanoMIL-100(Al), correlation peaks of strong intensity between all fluorine atoms of the lipid and the trimesate protons are observed. This unambiguously confirms the presence of the FO lipids in the bulk of the particles, i.e., in the pores of the MOF. In the ${ }^{19} \mathrm{~F}-{ }^{1} \mathrm{H} 2 \mathrm{D}$ NMR spectrum of FP@nanoMIL-100(Al) (Figure 7b), cross-peaks of strong intensity are observed between the $\mathrm{CFH}_{2}$ group and its neighboring $\mathrm{CH}_{2}$ groups from the lipid. Contrary to FO@nanoMIL-100(Al), the cross-peak between the $\mathrm{CFH}_{2}$ of the lipid and the proton of the trimesate has very low intensity, confirming its localization on the surface of the particle, and not inside the pores. The fact that these cross-peaks are observed shows that the F- 
$\mathrm{H}_{\text {trimesate }}$ distance is not very long, which in turn could indicate that the FP is folded on the nanoparticle surface (Figure 8) rather than standing in a brush-like manner (Figure 1).
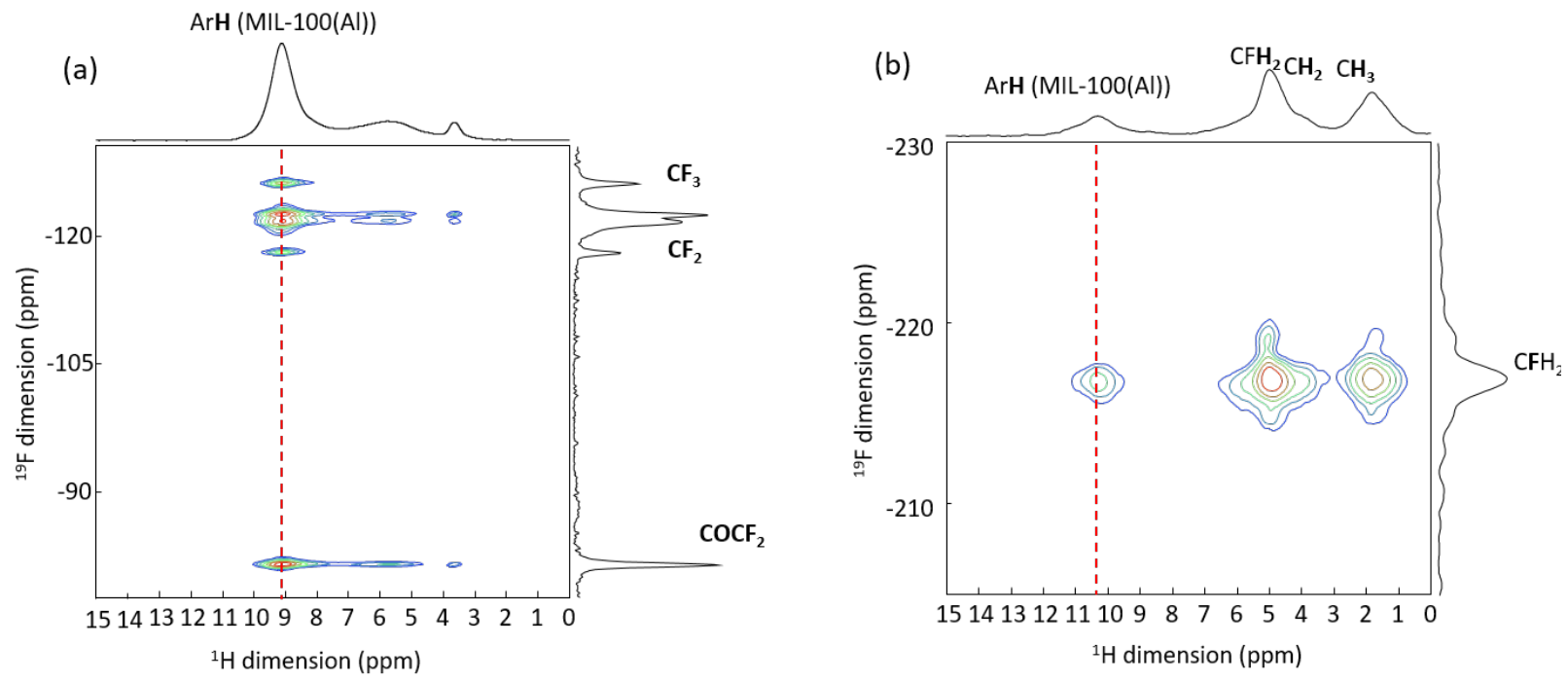

Figure 7. ${ }^{19} \mathrm{~F}-{ }^{1} \mathrm{H}$ 2D CPMAS NMR spectra (a) FO@nanoMIL-100(Al) and (b) FP@nanoMIL100(Al). The lines are assigned. The red dash line indicates the spatial proximity between the ${ }^{19} \mathrm{~F}$ resonances and the ${ }^{1} \mathrm{H}$ of the MOF.

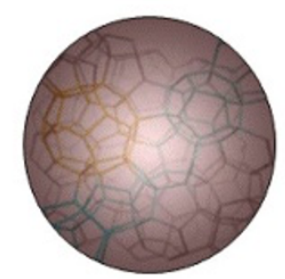

nanoMIL-100(Al)

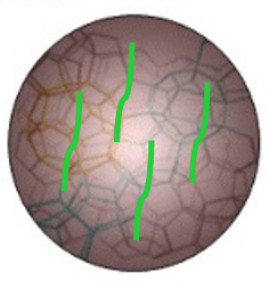

FO@nanoMIL-100(Al)

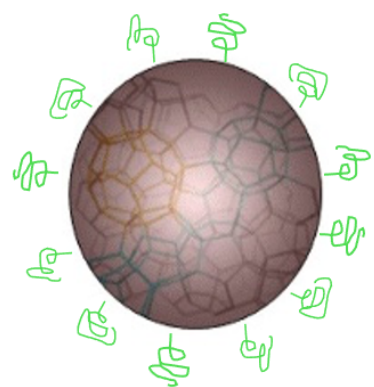

FP@nanoMIL-100(Al)

Figure 8. Schematic structure of nanoMIL-100 (left) and localization of FO (middle) and FP (right) inside and outside the nanoMOFs, respectively, as deduced from the NMR data. 


\section{Conclusions and Perspectives}

In conclusion, we have reported an investigation of the localization of two types of fluorinated lipids in nanoMIL-100(Al) particles. Although the ${ }^{27} \mathrm{Al}$ quadrupolar nucleus was initially considered as an ideal nucleus to probe the coating/MOF interactions, as was shown earlier for nanoMOFs coated with rigid cyclodextrin-based moieties, we found some limits in our the studied lipids-coated nanoMOFs, in which the high mobility of the lipids prevented efficient polarization transfer between the ${ }^{1} \mathrm{H} /{ }^{19} \mathrm{~F}$ species of the lipid and the ${ }^{27} \mathrm{Al}$ nuclei of the nanoMOF. These limits led us to use ${ }^{1} \mathrm{H}-{ }^{1} \mathrm{H}$ and ${ }^{1} \mathrm{H}-{ }^{19} \mathrm{~F}$ 2D NMR experiments. The low amount of water present in the pores of FO@nanoMIL-100(Al) and the cross-peaks of high intensity between ${ }^{19} \mathrm{~F}$ of the lipid and ${ }^{1} \mathrm{H}$ of the MOF linker strongly suggests that FO has successfully been incorporated inside the pores of the MOF. On the other hand, in FP@nanoMIL-100(Al) high amounts of water in the pores and cross-peaks of very low intensity between ${ }^{19} \mathrm{~F}$ of the lipid and ${ }^{1} \mathrm{H}$ of the MOF linker strongly suggests that FP stays on the surface of the particles, and is very likely folded on the NP surface. This ensemble of data allows accurate localization of F-lipids in nanoMOFs, an important criterion in view of in vivo application of these particles.

\section{Acknowledgments}

MP thanks the Région Centre-Val de Loire for a PhD fellowship. CMC is grateful for financial support from the Institut Universitaire de France (IUF). Financial support from the IRRMN-THC Fr3050 CNRS for conducting the research is gratefully acknowledged. This work was also supported by the Paris Ile-de-France Region - DIM "Respore". This work is supported by a public grant overseen by the French National Research Agency (ANR) as part of the “Investissements d'Avenir” program (Labex NanoSaclay, reference: ANR-10-LABX-0035). 


\section{References}

1 P Horcajada, T. Chalati, C. Serre, B. Gillet, C. Sebrie, T. Baati, J. F. Eubank, D. Heurtaux, P.

Clayette, C. Kreuz, J. S. Chang, Y. K. Hwang, V. Marsaud, P. N. Bories, L. Cynober, S. Gil, G.

Ferey, P. Couvreur, R. Gref, Nature Mater. 2010, 9, 172.

2 C. Adhikari, A. Das, A. Chakraborty, Mol. Pharmaceutics 2015, 12, 3158.

3 G. Chedid, A. Assin, Nanomater. 2018, 8, 916.

4 T. Simon-Yarza, A. Mielcarek, P. Couvreur, C. Serre, Adv. Mater. 2018, 30, 1707365.

5 I. Abánades Lázaro, R. S. Forgan, Coord. Chem. Rev. 2019, 380, 230.

6 W. Chen, C. Wu, Dalton Trans. 2018, 47, 2114.

7 P. Horcajada, R. Gref, T. Baati, P. K. Allan, G. Maurin, P. Couvreur, G. Férey, R. E. Morris, C. Serre, Chem. Rev. 2012, 112, 1232.

8 R. Gref, M. Lück, P. Quellec, M. Marchand, E. Dellacherie, S. Harnisch, T. Blunk, R. H. Müller, Colloids and Surfaces B: Biointerfaces 2000, 18, 301.

9 J. Soo Suk, Q. Xu, N. Kim, J. Hanes, L. M. Ensign, Adv. Drug Deliv. Rev. 2016, 99, 28.

10 S. Y. Fam, C. Fei Chee, C. Yeah Yong, K. Lian Ho, A. Razak Mariatulqabtiah, W. Siang Tan, Nanomater. 2020, 10, 787.

11 V. Agostoni, P. Horcajada, M. Noiray, M. Malanga, A. Aykac, L. Jicsinszky, A. VargasBerenguel, N. Semiramoth, S. Daoud-Mahammed, V. Nicolas, C. Martineau, F. Taulelle, J. Vigneron, A. Etcheberry, C. Serre, R. Gref, Sci. Reports 2015, 5, 7925.

12 A. Aykaç, M. Noiray, M. Malanga, V. Agostoni, J. M. Casas-Solvas, É. Fenyvesi, R. Gref, A. Vargas-Berenguel, Biochim. Biophys. Acta 2017, 1861, 1606. 
13 G. Cutrone, X. Li, J. M. Casas-Solvas, M. Menendez-Miranda, J. Qiu, G. Benkovics, D. Constantin, M. Malanga, B. Moreira-Alvarez, J. M. Costa-Fernandez, L. García-Fuentes, R. Gref, A. Vargas-Berenguel, Nanomater. 2019, 9, 1103.

14 X. Li, G. Salzano, J. Qiu, M. Menard, Kristian Berg, T. Theodossiou, C. Ladavière, R. Gref, Front. Bioeng. Biotechnol. 2020, 8, 1027.

15 A. M. Morawski, P. M. Winter, X. Yu, R. W. Fuhrhop, M. J. Scott, F. Hockett, J. D. Robertson, P. J. Gaffney, G. M. Lanza, S. A. Wickline, Magn. Reson. Med. 2004, 52, 1255.

16 K. C. Partlow, J. Chen, J. A. Brant, A. M. Neubauer, T. E. Meyerrose, M. H. Creer, J. A. Nolta, S. D. Caruthers, G. M. Lanza, S. A. Wickline, FASEB J. 2007, 21,1647.

17 L. Wu, F. Liu, S. Liu, X. Xu, Z. Liu, X. Sun, Int. J. Nanomedicine, 2020, 15, 7377.

18 B. E. G. Lucier, S. Chen, Y. Huang, Acc. Chem. Res. 2018, 51, 319.

19 E. Brunner, M. Rauche, Chem. Sci. 2020, 11, 4297.

20 E. Skorupska, A. Jeziorna, S. Kazmierski, M. J. Potrzebowski, Solid State Nucl. Magn. Reson. 2014, 57-58, 2 .

21 G. Mali, Looking into Metal-Organic Frameworks with Solid-State NMR Spectroscopy. In Metal-Organic Frameworks; Zafar, F., Sharmin, E., Eds.; InTech: London, United Kindom, 2016. 22 B. E. G. Lucier, S. Chen, Y. Huang, Acc. Chem. Res. 2018, 51, 319.

23 E. Brunner, M. Rauche, Chem. Sci. 2020, 11, 4297.

24 S. H. Li, Shenhui, O. Lafon, W. Y. Wang, Q. Wang, X. X. Wang, Y. Li, J. Xu, F. Deng, $A d v$. Mater., DOI: 10.1002/adma.202002879.

25 T. Čendak, E. Žunkovič, T. U. Godec, M. Mazaj, N. Z. Logar, G. Mali, J. Phys. Chem. C 2014, $118,6140$. 
26 S. Devautour-Vinot, C. Martineau, S. Diaby, M. Ben-Yahia, S. Miller, C. Serre, P. Horcajada, D. Cunha, F. Taulelle, G. Maurin, J. Phys. Chem. C 2013, 117, 11694.

27 M. Porcino, I. Christodoulou, M. Dang Le Vuong, R. Gref, C. Martineau-Corcos, RSC Adv., 2019, 9, 32472 .

28 X. Lin, K. Ideta, J. Miyawaki, Y. Wang, Y. Nishiyama, S. Yoon, I. Mochida, App. Magn. Reson. 2014, 45, 111.

29 C. Fernandez, M. Pruski, Recent Advances, Solid State NMR, Book Series: Topics in Current Chemistry, 2012, 306, 119.

30 Z. W. Yu, A. M. Zheng, Q. A. Wang, L. Chen, J. Xu, J. P. Amoureux, F. Deng, Angew. Chem. - Inter. Ed. 2010, 49, 8657.

31 Z. W. Yu, S. H. Li, Q. A. Wang, A. M. Zheng, X. Jun, L. Chen, F. Deng, J. Phys. Chem. C 2011, 115, 22320.

32 C.M. Morais, V. Montouillout, M. Deschamps, D. Iuga, F. Fayon, F. A. A. Paz, J. Rocha, C. Fernandez, D. Massiot, Magn. Reson. Chem. 2009, 47, 942

33 N. Malicki, G. Mali, A. A. Quoineaud, P. Bourges, S. L. Simon, F. Thibault-Starzyk, C. Fernandez, Microporous Mesoporous Mater. 2010, 129, 100.

34 L. Shenhui, F. Deng, Annual Reports on NMR Spectroscop. 2013, 78, 1.

35 C. Martineau-Corcos, J. Dědeček, F. Taulelle, Solid State Nucl. Magn. Reson. 2017, 84, 65.

36 M. Haouas, F. Taulelle, C. Martineau, Progress in NMR Spectrosc. 94-95 (2016) 11-36

37 C. Volkringer, D. Popov, T. Loiseau, G. Ferey, M. Burghammer, C. Riekel, M. Haouas, F. Taulclle, 2009, 21, 5695.

38 C. Volkringer, T. Loiseau, N. Guillou, G. Ferey, M. Haouas, F. Taulelle, N. Audebrand, I. Margiolaki, D. Popov, M. Burghammer, C. Riekel, Crystal Growth Des., 2009, 9, 2927. 
39 C. Volkringer, T. Loiseau, N. Guillou, G. Ferey, M. Haouas, F. Taulelle, E. Elkaim, N. Stock, Inorg. Chem., 2010, 49, 9852.

40 C. Volkringer, T. Loiseau, M. Haouas, F. Taulelle, D. Popov, M. Burghammer, C. Riekel, C. Zlotea, F. Cuevas, M. Latroche, D. Phanon, C. Knoefelv, P. L. Llewellyn, G. Ferey, Chem. Mater., 2009, 21, 5783.

41 T. Loiseau, C. Volkringer, M. Haouas, F. Taulelle, G. Ferey, C. R. Chim. 2015, 18, 1350.

42 T. Ahnfeldt, D. Gunzelmann, T. Loiseau, D. Hirsemann, J. Senker, G. Ferey, N. Stock, Inorg. Chem. 2009, 48, 3057.

43 T. Ahnfeldt, N. Guillou, D. Gunzelmann, I. Margiolaki, T. Loiseau, G. Ferey, J. Senker, N. Stock, Angew. Che. Int. Ed. 2009, 28, 5163.

44 R. Giovine, C. Volkringer, J. Trebosc, J.-P. Amoureux, T. Loiseau, O. Lafon, F. Pourpoint, Acta Crystallogrpahica C, 2017, 73, 176.

45 G. Mali, M. Mazaj, I. Arčon, D. Hanžel, D. Arčon, Z. Jagličić, J. Phys. Chem. Lett. 2019, 10, 1464.

46 A. García Márquez, A. Demessence, A. E. Platero-Prats, D. Heurtaux, P. Horcajada, C. Serre, J.-S. Chang, G. Férey, V. Antonio de la Peña-O'Shea, C. Boissière, D. Grosso, C. Sanchez, Eur. J. Inorg. Chem. 2012, 5165.

47 J. P Amoureux, C. Fernandez, S. Steuernagel, J. Magn. Reson. 1996, 123, 116.

48 Z. Gan, J. Magn. Reson. 2007, 184, 39.

49 B. Hu, J. Trébosc, J. P. Amoureux, J. Magn. Reson. 2008, 192, 112.

50 J. Trébosc, B. Hu, J. P. Amoureux, Z. Gan, J. Magn. Reson. 2007, 186, 220.

51 A. Brinkmann, A. P. M. Kentgens, J. Am. Chem. Soc. 2006, 128, 14758.

52 M. H. Levitt, Advances in NMR; Grant, D. M., Harris, R. K., Eds.; Encyclopedia of nuclear 
magnetic resonance; Wiley: Chichester, 2002; Vol. 9.

53 C. Martineau, F. Engelke, F. Taulelle, J. Magn. Reson. 2011, 212, 311.

54 D. Massiot, F. Fayon, M. Capron, I. King, S. Le Calvé, B. Alonso, J. O. Durand, B. Bujoli, Z. Gan, G. Hoatson, Magn. Reson. Chem. 2002, 40, 70.

55 Guide to Fluorine NMR for Organic Chemists-Chapter 2, Second Edition. William R. Dolbier, Jr. 2016 John Wiley \& Sons, Inc. Published 2016 by John Wiley \& Sons, Inc.

56 C.-M. Hu, Z.-Q. Xu, W.-Y. Huang, J. Fluor. Chem. 2009, 49, 433.

57 P. Paluch, N. Potrzebowska, A. M. Ruppert, M. J. Potrzebowski, Solid State Nucl. Magn. Reson. 2017, 84, 111.

58 G. Tricot, O. Lafon, J. Trébosc, L. Delevoye, F. Mear, L. Montagne, J.-P. Amoureux, Phys. Chem. Chem. Phys. 2011, 13, 16786. 